\title{
COVID-19-Induced Anxiety and Associated Factors Among Urban Residents in West Shewa Zone, Central Ethiopia, 2020
}

This article was published in the following Dove Press journal: Psychology Research and Behavior Management

\author{
Adamu Birhanu' \\ Takele Tiki' \\ Mulugeta Mekuria (iD) ${ }^{2}$ \\ Delelegn Yilma ${ }^{2}$ \\ Getu Melese ${ }^{3}$ \\ Benyam Seifu (iD) \\ 'Department of Psychiatry, College of \\ Medicine and Health Sciences, Ambo \\ University, Ambo, Ethiopia; ${ }^{2}$ Department \\ of Public Health, College of Medicine and \\ Health Sciences, Ambo University, Ambo, \\ Ethiopia; ${ }^{3}$ Department of Pharmacy, \\ College of Medicine and Health Sciences, \\ Ambo University, Ambo, Ethiopia; \\ ${ }^{4}$ Department of Midwifery, College of \\ Medicine and Health Sciences, Ambo \\ University, Ambo, Ethiopia
}

Background: The COVID-19 pandemic affects the public overall psychological status including anxiety. Assessing the perceived risk and preventive behaviors and COVID-19induced anxiety of every individual is crucial to be more effective in handling the outbreak. Purpose: This study intends to determine the status of perceived risk, preventive behavior, and induced anxiety regarding COVID-19 among urban residents in Ethiopia.

Methods: In this research a population-based, cross-sectional design was employed among 801 urban residents in West Shewa Zone, Ethiopia from June to October 2020 COVID-19 Induced Anxiety Scale (CIAS) was used, with CIAS score $\geq 80 \%$ taken as having anxiety. A Preventive Behavior towards COVID-19 Scale (PBCS) was used to measure the level of protective behavior. The data were gathered using CS Entry and analyzed with SPSS version 23.0. Basic descriptive analysis was conducted, and binary logistic regression analysis was carried out to determine the predictors associated with anxiety.

Results: Most of the study population, 716 (89.4\%), had moderate risk perception, and around $497(62.0 \%)$ of them had moderate preventive behavior against the pandemic. The proportion of COVID-19-induced anxiety disorder was found to be $18.1 \%$. The identified predictors associated with COVID-induced anxiety were: being widowed (AOR $=3.5 ; 95 \%$ CI: 1.7-7.6), lacking formal education $(\mathrm{AOR}=1.9 ; 95 \% \mathrm{CI}: 1.3-3.3)$, having history of psychoactive substance use $(\mathrm{AOR}=3.0 ; 95 \% \mathrm{CI}: 1.6-5.8)$, high protective behavior $(\mathrm{AOR}=2.2 ; 95 \% \mathrm{CI}: 1.5-3.3)$, low perceived risk $(\mathrm{OR}=3.7 ; 95 \% \mathrm{CI}: 1.5-12.4)$, and family history of mental illness (AOR=1.6; 95\% CI:0.7-3.8).

Conclusion and Recommendation: COVID-19-induced anxiety prevalence was $18.1 \%$. Risk perception regarding COVID was moderate. However, only $38.0 \%$ of the population had high preventive behavior against the pandemic. Hence, it is important to provide the continuous public health education necessary to promote preventive measures and minimize risky behaviors. Basic psychosocial help should be also provided for individuals suffering with COVID-19-induced anxiety.

Keywords: COVID-19 induced anxiety, perceived risk, protective behavior, Ethiopia

\section{Background}

In late December 2019, an outbreak of the novel coronavirus disease (nCOVID-19) started in Wuhan, China, and rapidly spread to the rest of the globe. On 11 March 2020, the WHO declared the outbreak a pandemic when the number of infected persons outside China had increased, and the number of affected countries tripled. $^{1-8}$ The safety of the community and awareness of the natural history of
Correspondence: Delelegn Yilma Ambo University, P.O. Box 19, Ambo, Ethiopia

Tel +25। 912310083

Email delelegniyilma@gmail.com 
COVID-19 are improved by protective behaviors including covering mouth and nose with masks, frequent handwashing, and keeping acceptable social distancing. The relationship between anxiety and protective can be described by the inverted U-shaped Fear Drive Model of Janis which demonstrates that a moderate level of fear motivates people to adopt protective behavior but when this level is too high or too low, people are more likely to engage in risky behaviors. ${ }^{9}$

As the COVID-19 illness points to a very uncertain future, the risk of anxiety among the overall population was raised. Anxiety is an effective emotional response to a threat, which can predict protective behaviors independent of the risk severity. In other words, worrying is a predictor of the individual's behaviors when facing a threat. Numerous factors can affect worry about a pandemic. This includes socio-demographic characteristics, social context, and individual values. ${ }^{10}$ Because of the sudden nature of the outbreak and the infectious power of the virus, it will inevitably cause people anxiety, depression, and other stress reactions. ${ }^{1,8}$

Socio-demographic characteristics, social context, and individual values were focused on in the present study because they are major contributing factors in determining an individual's mental health status. Studies indicated that the socio-economic impacts in Ethiopia are wide-ranging and serious, with the potential to become severe, depending on the combination of the pandemic's trajectory, the effects of counter-measures, and underlying and structural factors which in turn complicate the mental health status of the population. Social and individual values are also greatly affected by the pandemic. ${ }^{11,12}$ For instance, social distancing and lockdown due to the pandemic lead to the reduction of social support, social bonds, and social interaction. Therefore, as a result of reduced social interaction, those individuals with pre-existing mental health problems can be more stigmatized or discriminated against, which is a fertile ground for mental health deterioration. Similarly, the social contexts that can alleviate mental health problems could be varied from community to community, and an individual's perception about the pandemic has huge impact on the infection transmission rate in society. Existing factors leading to low socioeconomic status, such as poverty, low income, gender disparity, high rate of unemployment, and illiteracy as well as the lasting impact of sudden disruptions to financial stability in Ethiopia could also aggravate the condition. Hence, these factors could also be the barriers to applying the preventive measures and could worsen the mental health impacts of the pandemic. Therefore, comprehensive investigation of these factors is mandatory in order to design and implement comprehensive interventions that will reduce the transmission, protect community health, and lessen the mental health effects of the pandemic in Ethiopia. ${ }^{11-13}$

Africa is predominantly susceptible because $56 \%$ of the urban population is concentrated in overcrowded and poorly serviced slum dwellings and only $34 \%$ of the households have access to basic handwashing facilities. The majority of Africa's workforce is informally employed, and most cannot work from home. Of all the continents, Africa has the highest prevalence of comorbidities, like tuberculosis and HIV/AIDS. With lower ratios of hospital beds and health professionals to its population than other regions, high dependency on imports for its medicinal and pharmaceutical products, weak legal identity systems for direct benefit transfers, and weak economies that are unable to sustain health and lockdown costs, the continent is vulnerable. ${ }^{14}$

In Ethiopia, the first Coronavirus case was reported on 13 March 2020, and at the time of writing, there have been more than 120,348 confirmed cases and 1861 deaths as of 22 December $2020 .{ }^{15}$ Assessing the perceived risk and protective behaviors and COVID-19-induced anxiety of the population is crucial to be more effective in prevention and control activities towards the outbreak in this country. ${ }^{16,17}$ Therefore, the findings of this study can provide important additional evidence to the existing literature to aid further researchers as well as for the community.

\section{Methods and Materials Study Area and Study Design}

In this research, a population-based, cross-sectional design was employed among urban residents living in the West Shewa Zone, Oromia region, Central Ethiopia from June 2020 up to October 2020. West Shewa Zone is one of the largest zones in the Oromia region located 114 kilometers from Addis Ababa, the capital city of Ethiopia. Based on the 2019 West Shewa Zone health bureau report, the zone has 21 districts and 2,448,272 total inhabitants, of whom $1,331,860$ are males and $1,116,412$ are females. Adult urban residents who were aged eighteen and above living in the West Shewa Zone were the study population. 


\section{Sample Size Determination and Sampling Techniques}

The required sample size was determined with single proportion estimation formula by assuming the proportion of COVID-19-induced anxiety (P) of 50\%, with $95 \%$ confidence level and marginal error of $5 \%$, which yields a minimum sample size (n) of 384. After adding $10 \%$ for non-respondent rate and multiplying by a design effect of two to adjust for the sampling error due to the multi-stage sampling method we used and in order to increase the precision of the study estimates, the final sample size was 846. A multi-stage sampling technique was used to select the districts, villages, and study participants. Among twenty-one districts in West Shewa zone, eight of them were selected using a simple random sampling method, and two villages were randomly selected from each selected district. The lists of households for the selected villages were obtained from respective village administrative offices. Then, the total sample size was proportionally allocated for each selected village based on the number of the target population, and a simple random sampling method was used to select the required households. Adult permanent residents of the selected households were interviewed. If more than one adult resident was found, a lottery method was used to select the person to be interviewed.

\section{Data Collection Procedure}

Data were collected using an interviewer-administered pretested data collection questionnaire which was adopted by reviewing similar literatures. ${ }^{10,18-21}$ The questionnaire has socio-demographic, medical, and substance use history, perceived risk, protective behavior, and COVID-19induced anxiety assessment sections. Perceived risk was measured using 18 risk perception items and a four-point Likert scale $(1=$ strongly disagree, $2=$ disagree, $3=$ agree, and $4=$ strongly agree). For instance, participants' perceived susceptibility to getting COVID-19 infection, likelihood that they think family members or friends could get infected, perceived severity of symptoms and likelihood of dying from COVID-19, and perceived selfefficacy in terms of what they would do to protect themselves are the key measures included in perceived risk instrument. The perceived risk tool was used in different settings. ${ }^{19,21}$ In this study, the internal cosistency of the perceived risk instrument was good (Cronbach's alpha $=0.82$ ).
COVID-19-induced anxiety was assessed using the validated 6-item COVID-19 Induced Anxiety Scale (CIAS). Each item is graded on a five-point Likert scale ranging from 1 for totally disagree to 5 for totally agree. These items measured respondents' worries about being infected by COVID-19 (afraid to die if infected, feel anxious when any family member goes outside home during this COVID-19 outbreak, fear of individuals coming from the affected areas, would be restless and sleepless when I have fever or cough during COVID-19, and hearing COVID-19 outbreak updates increases anxiety and worry). The internal consistency of CIAS was fair (Cronbach's alpha $=0.78$ ). A validated Protective Behaviors towards COVID-19 Scale (PBCS-14 items) graded on a five-point Likert scale ( $1=$ strongly disagree, $2=$ disagree, $3=$ neutral, $4=$ agree, and $5=$ strongly agree) was used. For example, the behavioral measures included avoiding crowded areas, canceling unnecessary travel, keeping social distancing, frequent handwashing, and covering mouth and nose with a mask in public. The protective behavior instrument had good internal consistency (Cronbach's alpha=0.85). ${ }^{10}$ The data were collected by ten BSc health science graduates and five masters of public health (MPH) professionals who supervised the data collection process. Training was given to the assigned data collectors and supervisors about the assessment tools in order to maintain the data quality.

\section{Data Processing and Analysis Procedures}

Statistical Product and Service Solution (SPSS) 23.0 was used for the data analysis. In the statistical review of the results, the Kolmogorov-Smirnov test was used to determine whether the parameters were normally distributed. Descriptive statistics for continuous variables are shown as mean \pm standard deviation, and categorical variables are expressed as frequency and percentage. The overall perceived risk behavior score was classified as high $(\geq 80 \%)$, moderate $(50-79 \%)$, and low $(<50 \%)$ according to modified Bloom's cut-off value ${ }^{19}$ and was calculated from items regarding perceived susceptibility (6 items), severity (6 items), and efficacy (6 items) towards the COVID-19 pandemic. Negative items were scored reversely, and the sum of all 18 items was calculated to estimate perceived risk score. Therefore, the total perceived risk score possibly ranged from 18 to 72 points. Hence, scores of 18-35 were categorized as low, scores of 36-57 as moderate, and scores of 58-72 as high. CIAS $\geq 80 \%$ was taken as having anxiety. CIAS consists of 6 items scaled from 1 to 5 , so the minimum 
possible total score is 6 , and the maximum possible total point score would be 30 . Hence, CIAS scores ranging from 6 to 23 points were considered as no anxiety and scores from 24 to 30 as having anxiety. Protective behaviors were classified as high ( $\geq 80 \%)$, moderate $(50-79 \%)$, and low $(<50 \%)$ according to the modified Bloom's cut-off value. PBCS has 14 items scored on a five-point Likert scale with responses ranging from $1=$ strongly disagree to $5=$ strongly agree, hence the possible overall score ranged from 14 to 70 . PBCS total scores of 56-70 points indicated high protective behavior, scores of 35-55 points were classified as moderate, and scores of 14-34 points were seen as having low protective behavior. ${ }^{10}$ Binary logistic regression was used to examine the relationship between socio-demographic factors, perceived risk, and protective behavior towards COVID-19 and COVID-19-induced anxiety.

\section{Ethical Consideration}

Prior to data collection, an ethical clearance letter was obtained from the Ambo University, College of Medicine and Health Sciences ethical clearance committee. Then, a permission letter was also gained from each selected district, and written consent was taken from the study respondents after clearly explaining the objectives of the research. In addition, the participants were also informed that they may withdraw themselves at any stage of the data collection period. The study was also conducted in accordance with the Declaration of Helsinki.

\section{Results}

\section{Socio-Demographic Characteristics of Study Participants}

Among 846 samples, 801 participants responded to the study, representing a $94.7 \%$ response rate. The mean age (standard deviation) of the total participants was 34.8 $( \pm 14.0)$ years. Of the respondents, $415(51.8 \%)$ were males, $391(48.8 \%)$ were protestant Christians, and 444 (55.4\%) were married. Most of the study participants, 728 (90.9\%) were Oromo in ethnicity, and 705 (88.0\%) had formal education. Regarding occupational status, 228 (28.5\%) of respondents were farmers and 211 (26.3\%) were housewives. Besides, 628 (78.4\%) of participants had monthly family income less than 4000 Ethiopian Birr. Of the total respondents, $172(21.5 \%)$ indicated a history of substance use; 33 (4.1\%) of respondents reported a history of mental illness, and $53(6.6 \%)$ of participants reported a family history of mental illness (Table 1).
Table I Socio-Demographic Characteristics of Respondents, West Shewa Zone, Ethiopia, 2020

\begin{tabular}{|c|c|c|c|}
\hline \multicolumn{2}{|c|}{ Socio-Demographic Characteristics } & \multirow{5}{*}{$\begin{array}{c}\text { Frequency } \\
89 \\
509 \\
149 \\
54\end{array}$} & \multirow{5}{*}{$\begin{array}{c}\begin{array}{c}\text { Percent } \\
\text { (\%) }\end{array} \\
11.1 \\
63.5 \\
18.6 \\
6.7\end{array}$} \\
\hline Age (years) & $\leq 20$ & & \\
\hline & $21-40$ & & \\
\hline & $4 I-60$ & & \\
\hline & $>60$ & & \\
\hline \multirow[t]{2}{*}{ Sex } & Male & 415 & 51.8 \\
\hline & Female & 386 & 48.2 \\
\hline \multirow[t]{4}{*}{ Ethnicity } & Oromo & 728 & 90.9 \\
\hline & Amhara & 45 & 5.6 \\
\hline & Gurage & 19 & 2.4 \\
\hline & Others & 9 & I.I \\
\hline \multirow[t]{4}{*}{ Religion } & Orthodox & 331 & 41.3 \\
\hline & Protestant & 391 & 48.8 \\
\hline & Muslim & 42 & 5.2 \\
\hline & Others & 37 & 4.6 \\
\hline \multirow[t]{5}{*}{ Marital status } & Single & 225 & 28.1 \\
\hline & Married & 444 & 55.4 \\
\hline & Divorced & 45 & 5.6 \\
\hline & Widowed & 37 & 4.6 \\
\hline & Separated & 50 & 6.2 \\
\hline \multirow[t]{4}{*}{ Educational status } & $\begin{array}{l}\text { No formal } \\
\text { education }\end{array}$ & 96 & 12.0 \\
\hline & Grade I-8 & 213 & 26.6 \\
\hline & Grade 9-12 & 238 & 29.7 \\
\hline & $\begin{array}{l}\text { Certificate and } \\
\text { above }\end{array}$ & 254 & 31.7 \\
\hline \multirow[t]{6}{*}{ Occupational status } & Farmer & 228 & 28.5 \\
\hline & House wife & 211 & 26.3 \\
\hline & Merchant & 110 & 13.7 \\
\hline & Gov't & 51 & 6.4 \\
\hline & $\begin{array}{l}\text { employee } \\
\text { Student }\end{array}$ & 130 & 16.2 \\
\hline & House husband & 7I & 8.9 \\
\hline \multirow{4}{*}{$\begin{array}{l}\text { Monthly family income } \\
\text { (Birr) }\end{array}$} & $\leq 1000$ & 287 & 35.8 \\
\hline & $1001-2000$ & 175 & 21.8 \\
\hline & $200 I-4000$ & 166 & 20.7 \\
\hline & $>4000$ & 173 & 21.6 \\
\hline \multirow{2}{*}{$\begin{array}{l}\text { History of substance } \\
\text { use }\end{array}$} & Yes & 172 & 21.5 \\
\hline & No & 629 & 78.5 \\
\hline \multirow{2}{*}{$\begin{array}{l}\text { History of mental } \\
\text { illness }\end{array}$} & Yes & 33 & 4.1 \\
\hline & No & 768 & 95.9 \\
\hline \multirow{2}{*}{$\begin{array}{l}\text { Family history of } \\
\text { mental illness }\end{array}$} & Yes & 53 & 6.6 \\
\hline & No & 748 & 93.4 \\
\hline
\end{tabular}




\section{COVID-19-Induced Anxiety, Risk and Protective Behavior Towards COVID-19}

The overall perceived risk behavior score was calculated from items regarding perceived susceptibility ( 6 items), severity (6 items), and efficacy (6 items) towards the COVID-19 pandemic. Negative items were scored reversely and the sum of all items was calculated to estimate perceived risk score. By using Bloom's cut-off value these scores were categorized into low, moderate, and high-risk scores. Out of 801 respondents, 17 (2.1\%) were found to have low risk perception, a majority $716(89.4 \%)$ had medium risk perception, and the remaining 68 (8.5\%) had high risk perception of the COVID-19 pandemic.

The 14-item Protective Behaviors towards COVID-19 Scale (PBCS) was used to measure participants' protective behaviors against coronavirus infection. Among 801 total participants, $497(62.0 \% \%)$ had moderate protective behavior towards COVID-19, whereas 304 (38.0\%) of them had high protective behavior towards the COVID-19 pandemic. COVID-19-induced anxiety was assessed using the 6-item version of the COVID-19 Induced Anxiety Scale (CIAS); according to this, 145 (18.1\%) of respondents had COVID-19-induced anxiety disorder (Table 2).

\section{Factors Associated with COVID-19- Induced Anxiety}

Factors significantly associated with COVID-19-induced anxiety were: being widowed, lacking formal education, having a history of substance use, having a family history of mental illness, and displaying high protective

Table 2 COVID-19-Induced Anxiety, Risk, and Protective Behavior Towards COVID-19 Among Urban Residents in West Shewa Zone, Ethiopia, 2020

\begin{tabular}{|l|l|c|c|}
\hline \multicolumn{2}{|l|}{ Variables } & Frequency & $\begin{array}{c}\text { Percent } \\
\text { (\%) }\end{array}$ \\
\hline Protective behavior & $\begin{array}{l}\text { Highly } \\
\text { protective } \\
\text { Moderate } \\
\text { protective }\end{array}$ & 304 & 38.0 \\
\hline $\begin{array}{l}\text { Perceived risk } \\
\text { behavior }\end{array}$ & $\begin{array}{l}\text { High risk } \\
\text { Moderate risk } \\
\text { Low risk }\end{array}$ & $\begin{array}{c}716 \\
17\end{array}$ & $\begin{array}{c}89.5 \\
8.4\end{array}$ \\
\hline $\begin{array}{l}\text { COVID-19induced } \\
\text { anxiety }\end{array}$ & Yes & 145 & 18.1 \\
& No & 656 & 81.9 \\
\hline
\end{tabular}

behavior and low perceived risk behavior towards COVID-19 infection. Widowed participants had 3.5 times more COVID-19-induced anxiety compared with their married counterparts $(\mathrm{AOR}=3.5 ; 95 \% \mathrm{CI}: 1.7-7.6)$. Respondents who lacked formal education were twice as likely to have COVID-19-induced anxiety as formally educated participants $(\mathrm{AOR}=1.9 ; 95 \% \mathrm{CI}$ : 1.3-3.3). Similarly, individuals who had a history of substance use were 3.0 times more likely to have COVID-19induced anxiety than their counterparts $(A O R=3.0$; 95\% CI: 1.6-5.8). Moreover, a protective behavior towards COVID-19 was positively associated with COVID-19-induced anxiousness. Participants with high protective behavior had about twofold higher odds of COVID-19-induced anxiety compared to those with a moderate level of preventive behavior $(\mathrm{AOR}=2.2$; 95\% CI: 1.5-3.3). In addition, respondents with low perceived risk behavior towards COVID-19 had about 3.7 times higher odds of COVID-19-induced anxiousness than those individuals who had high perceived risk behavior about COVID-19 (OR=3.7; 95\% CI: 1.5-12.4) (Table 3).

\section{Discussion}

This study determined the magnitudes of perceived risk behavior and protective behavior towards COVID-19, prevalence, and factors associated with COVID-19induced anxiety in the West Shewa Zone urban community, Central Ethiopia. The study found that the prevalence of COVID-19-induced anxiety disorder was $18.1 \%$. The finding is lower compared to the magnitude reported in Addis Ababa communities, 36\%. ${ }^{17}$ Similarly, a systematic review and meta-analysis of seventeen articles reported a relatively higher anxiety rate $(31.9 \%)$ among the general public during the pandemic. ${ }^{22}$ However, the prevalence rate varied from $6 \%$ to $50 \%{ }^{22-24}$ Although there are scant data on how COVID-19 is increasing mental health conditions in Africa, some articles reported an increased rate of anxiety during the pandemic. ${ }^{25-27}$ These discrepancies could be attributed to differences in assessment tools, study period (data was being anxiousness toward pandemic increase at beginning, then decrease and finally collected after a few months when the community gives less attention. Community reaction and stable, ${ }^{28}$ variations in sociodemographic characteristics, environmental and sociocultural determinants that could contribute to handle the psychiatric issues during the pandemic. ${ }^{29}$ 
Table 3 Factors Associated with COVID-19-Induced Anxiety Among Urban Residents in West Shewa Zone, Central Ethiopia, 2020

\begin{tabular}{|c|c|c|c|c|c|}
\hline \multicolumn{2}{|l|}{ Variables } & \multicolumn{2}{|c|}{ Anxiety Disorder Frequency (\%) } & \multirow{2}{*}{ COR $(95 \% \mathrm{Cl})$} & \multirow[t]{2}{*}{ AOR $(95 \% \mathrm{Cl})$} \\
\hline & & Yes & No & & \\
\hline \multirow[t]{5}{*}{ Marital status } & Single & $37(16.4)$ & I88 (83.6) & $0.9(0.6-1.5)$ & $0.9(0.6-1.6)$ \\
\hline & Married & $76(17.1)$ & $368(82.9)$ & I & 1 \\
\hline & Divorced & $9(20.0)$ & $36(80.0)$ & $1.2(0.6-2.6)$ & $0.9(0.4-2.3)$ \\
\hline & Widowed & $15(40.5)$ & $22(59.5)$ & $3.3(1.6-6.7)^{* *}$ & $3.5(1.7-7.6)^{* *}$ \\
\hline & Separated & $8(16.0)$ & $42(84.0)$ & $0.9(0.4-2.1)$ & $0.7(0.3-1.7)$ \\
\hline \multirow[t]{2}{*}{ Educational status } & No formal education & $26(27.1)$ & $70(72.9)$ & $1.8(1.1-2.9)^{*}$ & $1.9(1.3-3.3)^{*}$ \\
\hline & Formal education & $119(16.9)$ & $586(83.1)$ & I & I \\
\hline \multirow[t]{2}{*}{ History of substance use } & Yes & $54(31.4)$ & $118(68.6)$ & $2.7(1.8-4.0)^{* *}$ & $2.4(1.6-3.7)^{* *}$ \\
\hline & No & $91(14.5)$ & $638(85.5)$ & 1 & I \\
\hline \multirow[t]{2}{*}{ History of mental illness } & Yes & $14(42.4)$ & $19(57.6)$ & $3.6(1.8-7.3)^{* *}$ & $1.6(0.7-3.8)$ \\
\hline & No & $|3|(\mid 7.1)$ & $637(82.9)$ & I & 1 \\
\hline \multirow[t]{2}{*}{ Family history of mental illness } & Yes & $24(45.3)$ & $29(54.7)$ & $4.3(2.4-7.6)^{* *}$ & $3.0(1.6-5.8)^{* *}$ \\
\hline & No & $|2|(16.2)$ & $627(83.8)$ & I & I \\
\hline \multirow[t]{2}{*}{ Protective behavior } & High & $75(24.7)$ & $229(75.3)$ & $1.9(1.4-2.9)^{* *}$ & $2.2(1.5-3.3)^{* *}$ \\
\hline & Moderate & $70(14.1)$ & $427(85.9)$ & I & I \\
\hline \multirow[t]{3}{*}{ Perceived risk behavior } & High risk & $12(17.6)$ & $56(82.4)$ & 1 & I \\
\hline & Moderate risk & $124(17.3)$ & $592(82.7)$ & $0.9(0.5-1.9)$ & $1.7(0.3-1.3)$ \\
\hline & Low risk & $9(52.9)$ & $8(47.1)$ & $4.1(1.3-13.4)^{*}$ & $3.7(1.5-12.4)^{*}$ \\
\hline
\end{tabular}

Notes: $* P$-value $<0.05$, **P-value $<0.001$.

Abbreviations: AOR, adjusted odds ratio; $\mathrm{Cl}$, confidence interval; $\mathrm{COR}$, crude odds ratio.

The study also indicated that a majority of the urban residents had a moderate degree of risk perception towards the COVID pandemic. This finding is congruent with studies conducted among Iranian and Myanmar communities. ${ }^{18,19}$ However, higher risk perception was reported among communities in Hong Kong ${ }^{20}$ and among college students in China. ${ }^{30}$ This could be due to variation in the outbreak magnitude, educational status, information accessibility, and the study period. ${ }^{18,28}$

In this study only $38.0 \%$ of urban residents had high preventive behavior towards the COVID-19 outbreak. This figure is lower than the finding from Iran that reported high preventive behaviors related to the COVID pandemic. The observed difference might be due to the variations in awareness status, knowledge as well as individuals' perception regarding the pandemic as many studies mentioned that better knowledge and risk perception enhance preventive behaviors. ${ }^{28,31,32}$ It might also be due to socioeconomic variations as studies indicated that better economic status enhances protective behaviors. ${ }^{33,34}$ The degree of applying preventive actions is also affected by the level of the epidemic, accessibility to the media, and information. ${ }^{28}$ Therefore, effective continuous health education is crucial to improve preventive actions and minimize risky behaviors. ${ }^{35}$

In developing countries like Ethiopia where mental health services are weak and inaccessible for a large proportion of the community, strengthening social support is crucial to prevent psychological problems during the pandemic. However, the pandemic weakens the existing social bonds and social support. At the early phase of the pandemic, social and material support such as distribution of preventive equipment like sanitizers and masks and provision of food aids was provided in order to minimize the spread of the outbreak. Awareness creation through religious organizations and educational and social institutions has been also done, promoting the sharing of materials and information among communities especially for more vulnerable population groups like females, the elderly, and children to reduce the social, economic, and mental health impacts of the pandemic. ${ }^{36}$ However, these kinds of support were limited to urban areas and were not sustained for a long period. Such support is crucial in helping people to stay at home and apply preventive measures which play their part in reducing 
transmission of the pandemic. Therefore, strengthening social support, including emotional aid and material aid, is strongly required in Ethiopia.

Educational status was significantly associated with COVID-19-induced anxiety. Respondents who lacked formal education were about twice as likely to have COVID-19-induced anxiety as their formally educated counterparts. This finding was in line with studies done in Russia ${ }^{37}$ and the Republic of China. ${ }^{38}$ However, in contrast to these findings, other researches done in lowincome countries reported higher rates of psychological problems during the COVID pandemic among people with higher educational status. ${ }^{17,39-41}$ This difference could be related to the variation between the educational statuses of the target population. Similarly, being widowed was significantly associated with COVID-19induced anxiety. This was supported by findings from other studies that in widowed individuals, in whom stressors of loss and loneliness are found, psychological problems like anxiety are elevated. ${ }^{42,43}$ Therefore, due emphasis should be given to low socio-economic groups of the population, and strengthening community and family support is important during the pandemic.

History of substance usage was another factor significantly correlated with anxiety caused by COVID-19 infection. This finding was congruent with previous evidence that there is anxiety induction with chronic substance use and withdrawal, which can initiate a feed-forward cycle of increased rate of showing psychiatric clinical manifestations and substance consumption. ${ }^{4-46}$ Likewise, having a family history of mental illness was related to COVID-19-induced anxiety. Convergent evidence from epidemiology and genetics suggests that shared genetic factors underpin an unexpectedly diverse range of psychiatric diseases. ${ }^{47}$ Moreover, research also indicated that persons with prior psychiatric history are more vulnerable to severe forms of mental disorders relative to the general public. ${ }^{48}$

Preventive behavior towards COVID-19 was found to be positively related to COVID-19-induced anxiety, whereas perceived risk behavior about this pandemic showed a negative correlation with anxiety. Similar studies also revealed that the level of anxiety enhances the possibility of applying preventive measures and increases risky conducts. ${ }^{10,21}$ But some studies showed anxiety causes risk-avoidant decisions and behaviors. $^{49,50}$ These could be explained by the theory that anxiety implies the potential threat and so helps people to perceive lower vulnerability to the threat. ${ }^{51,52}$
Nevertheless, anxiety can also have a negative effect, as it could accumulate and make one prone to risk-taking behaviors and a tendency to a low ability to execute coping behaviors. ${ }^{53-55}$ The results implied that vulnerability, perceived risk, as well as fear can considerably enhance preventive behaviors during the pandemic. ${ }^{56,57}$ Moreover, the presence of anxiety can influence the level of both preventive and risky behaviors during a pandemic. ${ }^{58,59}$

\section{Strength and Limitations of the Study}

The study is a community-based study based on adequate samples so that the observed findings are more likely to show the status of perceived risk behavior, protective behavior, and magnitude of COVID-19induced anxiety in the general population. However, it is difficult to show the temporal cause-effect relationship between the associated factors like perceived risk behavior and protective behavior towards COVID-19-induced anxiety as a result of the cross-sectional nature of the study. In addition, even though the tools used to assess the outcome variables are validated in other countries, they are not yet validated in Ethiopia. There are many social factors that may affect perceived risky behavior, protective behavior, and anxiety that could confound the findings of this study. Therefore, we recommend further longitudinal studies triangulated with qualitative methods to control the possible confounders.

\section{Conclusion and Recommendations}

The prevalence of COVID-19induced anxiety disorder was $18.1 \%$. The risk perception level towards COVID19 was low to high. However, only $8.5 \%$ of participants had a high-risk perception level towards the pandemic. Moreover, only $38.0 \%$ of respondents had high protective behavior towards the COVID-19 pandemic. Factors significantly associated with COVID-19-induced anxiety were widowed marital status, lacking formal education, having a history of substance use, family history of mental illness, high protective behavior, and low perceived risk behavior towards COVID-19 infection. Therefore, effective continuous health education is crucial to improve preventive actions and minimize risky behaviors. Moreover, strengthening community and family support, and providing effective health education is necessary to enhance healthy coping mechanisms and 
minimize unhealthy coping mechanisms in the general population. In addition, basic emotional and practical psychosocial support should be provided for people suffering due to the pandemic in order to minimize anxiety in Ethiopia.

\section{Data Sharing Statement}

The full data for this research are available through the corresponding author upon request.

\section{Ethics Approval and Consent for Publication}

Ethical clearance letter was obtained from the Ambo University, College of Medicine and Health Sciences ethical clearance committee. Then, a permission letter was also gained from each selected district, and written consent was taken from the study respondents after clearly explaining the objectives of the research. In addition, the participants were also informed that they may withdraw themselves at any stage of the data collection period. The study was also conducted in accordance with the Declaration of Helsinki.

\section{Acknowledgments}

The authors would like to thank the study respondents for their valuable information and Ambo University for the financial and materials support.

\section{Author Contributions}

All authors made substantial contributions to conception and design, acquisition of data, or analysis and interpretation of data; took part in drafting the article or revising it critically for important intellectual content; agreed to submit to the current journal; gave final approval of the version to be published; and agree to be accountable for all aspects of the work.

\section{Funding}

This study was financially supported by Ambo University.

\section{Disclosure}

All authors declare that they have no conflicts of interest for this work.

\section{References}

1. Inter-Agency Standing Committee (IASC). IASC interim brief note on addressing mental health and psychosocial aspects of covid-19 outbreak. IASC: Geneva; February 2020.
2. Xu Z, Shi L, Wang Y, et al. Pathological findings of COVID-19 associated with acute respiratory distress syndrome. Lancet Respir Med. 2020;8(4):420-422. doi:10.1016/S2213-2600(20)30076-X

3. Lai CC, Shih TP, Ko WC, Tang HJ, Hsueh PR. Severe acute respiratory syndrome coronavirus (SARS-CoV-2) and corona virus disease-2019 (COVID-19): the epidemic and the challenges. Int $J$ Antimicrob Agents. 2020;55(3):105924. doi:10.1016/j. ijantimicag.2020.105924

4. Abdulamir AS, Hafidh RR. The possible immunological pathways for the variable immuno pathogenesis of COVID - 19 infections among healthy adults, elderly and children. Electron J Gen Med. 2020;17(4): em202. doi:10.29333/ejgm/7850

5. World Health Organization. WHO director general's opening remarks at the media briefing on COVID-19-11 March 2020. Available from: https://www.who.int/dg/speeches/detail/who-director-general-s-open ing-remarks-at-the-media-briefingon-covid-19-11-March-2020.

6. World Health Organization. Statement on the second meeting of the International Health Regulations (2005) Emergency Committee regarding the outbreak of novel coronavirus $(2019 \mathrm{nCoV}) ; 2020$. Available from: https://www.who.int/news-room/detail/30-01-2020-statement-onthesecond-meeting-of-the-international-healthregulations-(2005)emergency-committee regarding-the-outbreak-of-novel-coronavirus -(2019ncov).

7. Mahtani S, Berger M, Grady SIM Hundreds of evacuees to be held on bases in California; Hong Kong and Taiwan restrict travel from mainland China. The WashingtonPost. 2020.

8. Lancet T. COVID-19: too little, too late? Lancet. 2020;395 (10226):755. doi:10.1016/S0140-6736(20)30522-5

9. Day M. Covid-19: surge in cases in Italy and South Korea makes pandemic look more likely. BMJ. 2020;368:m751. doi:10.1136/bmj.m751

10. Riad A, Huang Y, Zheng L, Elavsky S. COVID-19 induced anxiety and protective behaviors during COVID-19 outbreak: scale development and validation; 2020

11. United Nations (UN), Ethiopia: socio-Economic impact of COVID19 in Ethiopia. Addis Ababa, Ethiopia; May 2020.

12. Josephson A, Kilic T, Michler D. Socio-Economic Impacts of COVID-19 in Four African Countries. Policy Research Working Paper. Development Economics Development Data Group; 2020.

13. UNESCO. Socio-economic and cultural impacts of COVID-19 on Africa. UNESCO Responses. 2020.

14. Canadian mental Health association. COVID-19 and anxiety. October, 2020.

15. United Nation economic Commission For Africa. COVID-19 in Africa: protecting lives and economies. April 2020

16. Girma S, Agenagnew L, Beressa G, Tesfaye Y, Alenko A. Risk perception and precautionary health behavior toward COVID-19 among health professionals working in selected public university hospitals in Ethiopia. PLoS One. 2020;15(10):e0241101. doi:10.1371/journal.pone. 0241101

17. Kassaw C. The magnitude of psychological problem and associated factor in response to COVID-19 pandemic among communities living in Addis Ababa, Ethiopia, March 2020: a cross-sectional study design. Psychol Res Behav Manag. 2020;13:631-640. doi:10.2147/ PRBM.S256551

18. Aghababaei S, Bashirian S, Soltanian A, et al. Perceived risk and protective behaviors regarding COVID-19 among Iranian pregnant women. Middle East Fertil Soc J. 2020;25(1):29. doi:10.1186/ s43043-020-00038-z

19. Mya KS, Aye SM, Hlaing WA, et al. Awareness, perceived risk and protective behaviours of Myanmar adults on COVID-19. Int J Community Med Public Health. 2020;7(5):5. doi:10.18203/ 2394-6040.ijcmph20201530

20. Kwok KO, Li KK, Chan HH, et al. Community responses during the early phase of the COVID-19 epidemic in Hong Kong: risk perception, information exposure and preventive measures. medRxiv. 2020. http://medrxiv.org/content/early/2020/02/27/2020.02.26.20028217 
21. Yıldırım M, Güle A. Factor analysis of the COVID-19 perceived risk scale: a preliminary study. Death Stud. 2020;1-8. doi:10.1080/ 07481187.2020 .1784311

22. Salari N, Hosseinian-Far A, Jalali R, et al. Prevalence of stress, anxiety, depression among the general population during the COVID-19 pandemic: a systematic review and meta-analysis. Global Health. 2020;16(1):57. doi:10.1186/s12992-020-00589-w

23. Ren Z, Zhou Y, Liu Y. The psychological burden experienced by Chinese citizens during the COVID-19 outbreak: prevalence and determinants. Public Health. 2020;20:1617.

24. Li Q, Miao Y, Zeng X, et al. Prevalence and factors for anxiety during the coronavirus disease 2019 (COVID-19) epidemic among the teachers in China. $J$ Affect Disord. 2020;277:153-158. doi:10.1016/j.jad.2020.08.017

25. Arafa A, Mohamed A, Saleh L, Senosy S. Psychological impacts of the COVID-19 pandemic on the public in Egypt. Community Ment Health J. 2021;57(1):64-69. doi:10.1007/s10597-020-00701-9

26. Olasenia AO, Akinsolab OS, Agberotimic SF, Oguntayoa R. Psychological distress experiences of Nigerians during Covid-19 pandemic; the gender difference. Soc Sci Humanit Open. 2020;2 (1):100052. doi:10.1016/j.ssaho.2020.100052

27. Kim A, Nyengerai T, Mendenhall E. Evaluating the mental health impacts of the COVID-19 pandemic in urban South Africa: perceived risk of COVID-19 infection and childhood trauma predict adult depressive symptoms. medRxiv. 2020. doi:10.1101/ 2020.06.13.20130120

28. Akdeniz G, Kavakci M, Guzogok M, et al. A survey of attitudes, anxiety status, and protective behaviors of the university students during the covid-19 outbreak in Turkey. Front Psychiatry. 2020;11:695. doi:10.3389/fpsyt.2020.00695

29. Endomba FT, Angong Wou D, Danwang C. Mental health during the coronavirus disease 2019 (Covid-19) pandemic: more is still to be done. Pan Afr Med J. 2020;35(2):7. doi:10.11604/pamj. supp.2020.35.2.22605

30. Ding Y, Du X, Li Q, et al. Risk perception of coronavirus disease 2019 (COVID-19) and its related factors among college students in China during quarantine. PLoS One. 2020;15(8):e0237626. doi:10.1371/journal.pone.0237626

31. Brug J, Aro AR, Richardus JH. Risk perceptions and behaviour: towards pandemic control of emerging infectious diseases. International research on risk perception in the control of emerging infectious diseases. Int J Behav Med. 2009;16(1):3-6. doi:10.1007/ s12529-008-9000-x

32. Vartti AM, Oenema A, Schreck M, et al. SARS knowledge, perceptions, and behaviors: a comparison between finns and the dutch during the SARS outbreak in 2003. Int J Behav Med. 2009;16 (1):41-48. doi:10.1007/s12529-008-9004-6

33. Wise T, Zbozinek TD, Michelini G, Hagan CC. Changes in risk perception and protective behavior during the first week of the COVID-19 pandemic in the United States. PsyArXiv. 2020.

34. Chandrasekaran N, Marotta M, Taldone S, Singh V, Koru-Sengul T, Curry C. Socioeconomic disparities in knowledge and behaviors of zika virus in pregnant women. Obstet Gynecol. 2018;131(1):109S110S. doi:10.1097/01.AOG.0000533471.93417.4f

35. Goodwina R, Wiwattanapantuwongb J, Tuicomepeeb A, Suttiwanb P, Watakakosolb R. Anxiety and public responses to covid-19: early data from Thailand. J Psychiatr Res. 2020;129:118-121. doi:10.1016/ j.jpsychires.2020.06.026

36. Hailemariam M. COVID-19 in Ethiopia: assessment of how the ethiopian government has executed administrative actions and managed risk communications and community engagement. Risk Manag Healthc Policy. 2020;13:2803-2810. doi:10.2147/RMHP.S278234
37. Sorokin MY, Kasyanov ED, Rukavishnikov GV, et al. Structure of anxiety associated with the COVID-19 pandemic in the Russian-speaking sample: results from on-line survey. MedRxiv. 2020;1.

38. Liang L, Ren H, Cao R, et al. The effect of COVID-19 on youth mental health. Psychiatr Q. 2020;21:1-2.

39. Moghanibashi-Mansourieh A. Assessing the anxiety level of Iranian general population during COVID-19 outbreak. Asian J Psychiatr. 2020;51:102076. doi:10.1016/j.ajp.2020.102076

40. Wang Y, Di Y, Ye J, Wei W. Study on the public psychological states and its related factors during the outbreak of coronavirus disease 2019 (COVID-19) in some regions of China. Psychol Health Med. 2020;30:1-10

41. Zhang Y, Ma ZF. Impact of the COVID-19 pandemic on mental health and quality of life among local residents in Liaoning Province, China: a cross-sectional study. Int J Environ Res Public Health. 2020;17(7):2381. doi:10.3390/ijerph17072381

42. Sediri S, Zgueb Y, Ouanes S, Ouali U, Bourgou S. Women's mental health: acute impact of COVID-19 pandemic on domestic violence. Arch Womens Ment Health. 2020. doi:10.1007/s00737020-01082-4

43. Onrust SA, Cuijpers P. Mood and anxiety disorders in widowhood: a systematic review. Aging Ment Health. 2006;10(4):327-334. doi:10.1080/13607860600638529

44. Czeisler ME, Lane MA, Petrosky E, et al. Mental health, substance use, and suicidal ideation during the COVID-19 pandemic -United States. MMWR Morb Mortal Wkly Rep. 2020;69:32.

45. Back SE, Brady KT. Anxiety disorders with comorbid substance use disorders: diagnostic and treatment considerations. Psychiatr Ann. 2008;38(11):724-729. doi:10.3928/00485713-20081101-01

46. Smith JP, Book S. Anxiety and substance use disorders: a review. Psychiatr Times. 2008;25(10):19-23.

47. McGrath JJ, Wray NR, Pedersen CB, Mortensen PB, Greve A, Petersen L. The association between family history of mental disorders and general cognitive ability. Transl Psychiatry. 2014;4(7): e412. doi:10.1038/tp.2014.60

48. Solomou I, Constantinidou F. Prevalence and predictors of anxiety and depression symptoms during the COVID-19 pandemic and compliance with precautionary measures: age and sex matter. Int J Environ Res Public Health. 2020;17(14):4924. doi:10.3390/ ijerph17144924

49. Maner JK, Richey JA, Cromer K, et al. Dispositional anxiety and risk-avoidant decision-making. Pers Individ Dif. 2007;42 (4):665-675. doi:10.1016/j.paid.2006.08.016

50. Raghunathan R, Pham MT. All negative moods are not equal: motivational influences of anxiety and sadness on decision making. Organ Behav Hum Decis Process. 1999;79(1):56-77. doi:10.1006/ obhd.1999.2838

51. Barlow DH. Anxiety and Its Disorders: The Nature and Treatment of Anxiety and Panic. Guilford Press; 2002.

52. Butler G, Mathews A. Anticipatory anxiety and risk perception. Cogn Ther Res. 1987;11(5):551-565. doi:10.1007/BF01183858

53. Auerbach RP, Abela JR, Ho M-H. Responding to symptoms of depression and anxiety: emotion regulation, neuroticism, and engagement in risky behaviors. Behav Res Ther. 2007;45(9):2182-2191. doi:10.1016/j.brat.2006.11.002

54. Cicchetti D, Ackerman BP, Izard CE. Emotions and emotion regulation in developmental psychopathology. Dev Psychopathol. 1995;7 (1):1-10. doi:10.1017/S0954579400006301

55. Cooper ML, Agocha VB, Sheldon MS. A motivational perspective on risky behaviors: the role of personality and affect regulatory processes. J Pers. 2000;68(6):1059-1088. doi:10.1111/14676494.00126 
56. Yıldırım M, Geçer E, Akgül Ö. The impacts of vulnerability, perceived risk, and fear on preventive behaviours against COVID-19. Psychol Health Med. 2020. doi:10.1080/13548506.2020.1776891

57. Magson NR, Freeman JY, Rapee RM, et al. Risk and protective factors for prospective changes in adolescent mental health during the COVID-19 pandemic. $J$ Youth Adolesc. 2020;1-4.

58. Costa MR, Rocha MF, Santos GCJ, et al. Mental health and COVID-19 infection: systematic review in human cross-sectional studies. Health Sci J. 2020;(1):009.
59. Torales J, O'Higgins M, Castaldelli-Maia JM, Ventriglio A. The outbreak of COVID-19 coronavirus and its impact on global mental health. Int J Soc Psychiatr. 2020;20764020915212. doi:10.1177/ 0020764020915212

\section{Publish your work in this journal}

Psychology Research and Behavior Management is an international, peer-reviewed, open access journal focusing on the science of psychology and its application in behavior management to develop improved outcomes in the clinical, educational, sports and business arenas. Specific topics covered in the journal include: Neuroscience, memory and decision making; Behavior modification and management; Clinical applications; Business and sports performance management; Social and developmental studies; Animal studies. The manuscript management system is completely online and includes a very quick and fair peer-review system, which is all easy to use. Visit http://www. dovepress.com/testimonials.php to read real quotes from published authors. 